\title{
National Cancer Institute's Cancer Disparities Research Partnership program: experience and lessons learned
}

\section{Rosemary S. L. Wong ${ }^{1}$, Bhadrasain Vikram ${ }^{1}$, Frank S. Govern ${ }^{1}$, Daniel G. Petereit ${ }^{2}$ *, Patrick D. Maguire ${ }^{3}$, Maggie R. Clarkson ${ }^{4}$, Dwight E. Heron ${ }^{5}$ and C. Norman Coleman ${ }^{1}$}

${ }^{1}$ Radiation Research Program, Division of Cancer Treatment and Diagnosis, National Cancer Institute, Rockville, MD, USA

${ }^{2}$ Walking Forward Program, Rapid City Regional Hospital, Rapid City, SD, USA

${ }^{3}$ Coastal Carolina Radiation Oncology, Wilmington, NC, USA

${ }^{4}$ Singing River Health System, Pascagoula, MS, USA

${ }^{5}$ University of Pittsburgh Medical Center McKeesport, McKeesport, PA, USA

\section{Edited by:}

Soren M. Bentzen, University of

Maryland School of Medicine, USA

\section{Reviewed by:}

Valdir Carlos Colussi, UH Seidman

Case Medical Center, USA

Anuja Jhingran, M.D. Anderson

Cancer Center, USA

*Correspondence:

Daniel G. Petereit, FASTRO,

Department of Radiation Oncology,

John T. Vucurevich Cancer Care

Institute, Rapid City Regional

Hospital, 353 Fairmont Boulevard,

Rapid City, SD 57701, USA

e-mail: dpetereit@regionalhealth.com
Purpose: To increase access of underserved/health disparities communities to National Cancer Institute $(\mathrm{NCl})$ clinical trials, the Radiation Research Program piloted a unique model - the Cancer Disparities Research Partnership (CDRP) program. CDRP targeted community hospitals with a limited past $\mathrm{NCl}$ funding history and provided funding to establish the infrastructure for their clinical research program.

Methods: Initially, 5-year planning phase funding was awarded to six CDRP institutions through a cooperative agreement (U56). Five were subsequently eligible to compete for 5year implementation phase (U54) funding and three received a second award. Additionally, the $\mathrm{NCl}$ Center to Reduce Cancer Health Disparities supported their U56 patient navigation programs.

Results: Community-based hospitals with little or no clinical trials experience required at least a year to develop the infrastructure and establish community outreach/education and patient navigation programs before accrual to clinical trials could begin. Once established, CDRP sites increased their yearly patient accrual mainly to $\mathrm{NCl}$-sponsored cooperative group trials $(\sim 60 \%)$ and Principal Investigator/mentor-initiated trials $(\sim 30 \%)$. The total number of patients accrued on all types of trials was 2,371, while 5,147 patients received navigation services.

Conclusion: Despite a historical gap in participation in clinical cancer research, underserved communities are willing/eager to participate. Since a limited number of cooperative group trials address locally advanced diseases seen in health disparities populations; this shortcoming needs to be rectified. Sustainability for these programs remains a challenge. Addressing these gaps through research and public health mechanisms may have an important impact on their health, scientific progress, and efforts to increase diversity in $\mathrm{NCl}$ clinical trials.

Keywords: cancer disparities, underserved populations, patient accrual, access to clinical trials, clinical research

\section{INTRODUCTION}

The Cancer Disparities Research Partnership (CDRP) pilot program was initiated by the radiation research program (RRP) within the National Cancer Institute (NCI)'s Division of Cancer Treatment and Diagnosis (DCTD) in 2002 as a novel strategy to address the cancer health disparities that exist in racial, ethnic,

Abbreviations: ACS, American Cancer Society; AI, American Indian; ASTRO, American Society for Radiation Oncology; ATM, ataxia telangiectasia mutated gene; BSA, Board of Scientific Advisors for National Cancer Institute; CCRO, Coastal Carolina Radiation Oncology; CCOP, Community Clinical Oncology Program; CDRP, Cancer Disparities Research Partnership; CRCHD, Center to Reduce Cancer Health Disparities; CRR, Community Research Representative; CTOC, Clinical Trials Operating Committee; DCTD, Division of Cancer Treatment and Diagnosis; IAEA, International Atomic Energy Agency; IRB, Institutional Review Board; MBCCOP, Minority-Based Community Clinical Oncology Program; NACR, Native minority, and underserved populations within the United States (1). Over half of all cancer patients are treated with radiation alone or in combination with surgery or chemotherapy. This program was focused at radiation oncologists in communitybased hospitals and cancer centers that predominantly serve minority/underserved populations. Since the goal was to reach

American Cancer Research; NCI, National Cancer Institute; NCORP, National Cancer Institute Community Oncology Research Program; NHRMC, New Hannover Regional Medical Center; NIH, National Institute of Health; PACT, Program of Action for Cancer Therapy; PI, principal investigator; RCRH, Rapid City Regional Hospital; RFA, request for application; RRP, Radiation Research Program; RTOG, radiation therapy oncology group; SENC, Southeastern North Carolina; SRHS, Singing River Health System; UAB, University of Alabama Birmingham; UPMC, University of Pittsburgh Medical Center; WFP, Walking Forward Program. 
populations not having access to NCI clinical trials, application criteria included limited participation in clinical trials, and NCI grant funding $<\$ 100,000 /$ year. Utilizing a U56 planning cooperative agreement, funding went directly to community-based institutions to establish the clinical research infrastructure required for their populations to access NCI-sponsored radiation oncologybased clinical trials. CDRP sites were required to identify academic cancer centers or mentors experienced in NCI-sponsored clinical trials as partners who received limited funding from the grantee. To facilitate the mentoring relationships, a TELESYNERGY ${ }^{\text {тм }}$ (2), telemedicine system was provided to both grantee and primary mentor. Furthermore, NCI's Center to Reduce Cancer Health Disparities (CRCHD) provided supplemental funding to establish a patient navigation program addressing the specific needs of grantee's targeted populations.

The primary goal was to increase accrual of minority/underserved populations into NCI-sponsored clinical trials. Other objectives were: (1) increasing the number of staff involved in cancer health disparities research; (2) assessing the value of implementing the TELESYNERGYTM telemedicine system; (3) implementing an appropriate patient navigation program; and (4) determining whether this pilot would work in community-based institutions not historically involved in clinical research.

\section{MATERIALS AND METHODS \\ PROCESS FOR APPROVAL OF CDRP CONCEPT INITIATIVE AND REISSUANCE}

Following an NIH/NCI portfolio analysis, which determined a need for the proposed program, the CDRP concept was approved by the NCI's Board of Scientific Advisors and the request for application (RFA-CA-02-002), was issued in October 2001. An NCI Special Emphasis Panel reviewed six applications and two awards were made in September 2002. Since initial funding was approved for up to six awards, RFA-CA-03-018 was issued in August 2002 and four additional awards were made out of eight reviewed applications producing a success rate of $43 \%$ from both RFAs. Table 1 includes information on the grantees, Principal Investigators (PIs), mentors, service areas, and target populations.

The formal process for reissuance of any currently funded NCI program changed in 2006 and required an external program evaluation. NOVA Research Company (3) was awarded the 5-year U56 CDRP Process and Outcome Evaluation contract, which helped generate the programmatic assessment data. The reissuance process used NOVA's yearly CDRP Program Evaluation Reports (2006-2008) containing qualitative and quantitative data and the evaluation report by the CDRP Program Expert Committee (see Supplementary Material). This Expert Committee and CDRP PIs met annually at the American Society for Radiation Oncology (ASTRO) meeting to help RRP evaluate yearly progress and make recommendations for program improvement. The BSA recommended not expanding the program, but to accept applications only from the five funded grantees in a limited competition RFA-CA-09-502 (October 2008). After the Special Emphasis Panel review, 5-year U54 implementation awards were made to Rapid City Regional Hospital (RCRH), New Hanover Regional Medical Center (NHRMC), and Singing River Health
System (SRHS), while UPMC McKeesport Hospital received a 2-year phase out award.

\section{METRICS OF SUCCESS}

The metrics of success were:

1) Could a community-based hospital/cancer center establish a clinical research infrastructure within a reasonable period and accrue patients into radiation oncology-based clinical trials?

2) Was participation of underserved populations in NCIsponsored clinical trials increased?

3) Were mentors helpful in providing necessary training, support, and advice to the grantees?

4) Was the TELESYNERGYTM telemedicine system beneficial to the CDRP programs?

5) Was the CDRP grantee successful in increasing the number of physicians/other staff interested in cancer disparities research?

6) Was the CDRP site successful in disseminating program results through publications/presentations at national meetings?

\section{RESULTS}

\section{ESTABLISHMENT OF INFRASTRUCTURE}

Establishing the clinical research infrastructure was challenging because institutions were unfamiliar with its value for their patients. Despite all PIs having prior clinical trials experience, it took many months to educate the hospital administration about the benefits for their patients by participating in NCI clinical trials. By offering trials near their hometowns, patients can access these clinical advances without traveling great distances.

Findings from the U56 pilot program revealed important and unique issues regarding outreach to disparities populations not encountered at academic cancer centers and their community oncology affiliates. Disparities researchers needed sufficient time to succeed in: (1) recruiting personnel due to challenges in finding qualified staff to fill positions (e.g., program/grant manager, clinical research nurse/coordinator, data manager, patient navigator, and regulatory affairs expert for writing clinical protocols); (2) identifying a back-up PI after the loss of the primary PI at Laredo Medical Center; (3) establishing an outreach program so the community gained familiarity and trust with the PI and the research team $(4,5)$; and $(4)$ surveying the populations to determine their knowledge, attitudes, perceived barriers, and needs.

\section{PARTICIPATION IN CLINICAL TRIALS}

After the infrastructure was established, there was steady patient accrual onto various NCI clinical trials (Table 2). The type of trials most useful to the grantees is discussed below. The fluctuation seen in patient accruals was due to the limited number of cooperative group trials available for minority/underserved populations presenting with late-stage disease and co-morbidities. The restrictive eligibility criteria for many cooperative group trials resulted in low eligibility rates, averaging only $20-24 \%$ during both U56 and U54 phases (Table 3) (6).

\section{MENTORING AND PARTNERSHIP}

All grantees selected an NCI-designated Comprehensive Cancer Center as a primary or secondary (Laredo) mentor (Table 1) 
Table 1 | CDRP grantees, program title, Pls, mentors, service areas, and their target populations.

\begin{tabular}{|c|c|c|c|}
\hline Award year & Grantee/principal investigator (PI) & $\begin{array}{l}\text { Service area } \\
\text { population }\end{array}$ & Target population \\
\hline FY02 & $\begin{array}{l}\text { Rapid City Regional Hospital, Rapid City, South Dakota } \\
\text { Program name: Walking Forward (WF) } \\
\text { PI: Daniel G. Petereit, MD } \\
\text { Primary mentor: University of Wisconsin-Madison } \\
\text { Secondary mentor: Mayo Clinic in Rochester, MN }\end{array}$ & 300,000 & $\begin{array}{l}\text { American Indian/Native } \\
\text { American }\end{array}$ \\
\hline FY03 & $\begin{array}{l}\text { Daniel Freeman Memorial Hospital } \\
\text { Inglewood, CA, USA } \\
\text { Program name: Urban Latino African American Cancer (ULAAC) Disparities Project } \\
\text { PI: Michael L. Steinberg, MD } \\
\text { Primary Mentor: University of Southern California } \\
\text { Secondary Mentor: RAND Corporation, Santa Monica, CA }\end{array}$ & 100,000 & $\begin{array}{l}\text { African American } \\
\text { Hispanic/Latino }\end{array}$ \\
\hline FY03 & $\begin{array}{l}\text { New Hanover Regional Medical Center } \\
\text { Wilmington, North Carolina } \\
\text { Program name: Improving Cancer Outcomes for African-Americans } \\
\text { PI: Patrick D. Maguire, MD } \\
\text { Primary mentor: University of North Carolina-Chapel Hill }\end{array}$ & 616,000 & $\begin{array}{l}\text { African American } \\
\text { Urban/Rural Poor }\end{array}$ \\
\hline FY03 & $\begin{array}{l}\text { Singing River Hospital; Pascagoula, Mississippi } \\
\text { Program name: The Mississippi/Alabama Radiation Oncology Research Partnership } \\
\text { PI: Raymond Wynn, MDe } \\
\text { Primary mentor: University of Alabama at Birmingham } \\
\text { Secondary mentor: University of Mississippi Medical Center }\end{array}$ & 200,000 & African American \\
\hline
\end{tabular}

a Rapid City changed its CDRP program name early in program development from "Enhancing Native American Participation in Radiation Therapy Trials" to "Walking Forward," which was considered more culturally appropriate for their target American Indian patients.

${ }^{b}$ CDRP grant was relinquished in 2007 due to inability to find a qualified radiation oncologist to become PI when original PI resigned in 2006.

${ }^{\circ}$ Grant was changed to Centinela Freeman in 2004 and later was transitioned to Twenty-First Century Oncology at the Santa Monica Cancer Treatment Center in 2008.

${ }^{d}$ Dr. David Khan is the current CDRP PI and Dr. Michael Steinberg is co-PI.

${ }^{e}$ Dr. Raymond Wynn resigned in 2005 and Dr. W. Sam Dennis became the new PI.

based on clinical research expertise and/or an existing relationship; many also selected secondary partners to address specific needs. An important lesson learned was the need for the grantee to work immediately with the academic center's grants research office to obtain details on job descriptions, guidance for establishing an Institutional Review Board (IRB), and assistance in grant management. Given the complexity of a clinical trials infrastructure, grantees required a year or more before their disparity program was fully operational leading some to restructure their awards to allow an additional year.

\section{DEVELOPING CANCER DISPARITIES RESEARCH INTEREST AND PATIENT NAVIGATION}

Because of the limited availability of cooperative group trials as noted above, the grantees used two approaches to expand protocol participation: (1) development of PI-initiated clinical trials targeting stage of disease and/or including shorter radiation therapy schedules to address patients' transportation or accommodations barriers $(7,8)$ and (2) expanding access to other NCIsponsored clinical trials beyond radiation oncology, to include surgical/medical oncology trials (Table 2). This expansion was 
Table 2 | Cumulative number of patients accrued to different types of clinical trials by fiscal year in U56 planning phase and cumulative for U54 phase.

\begin{tabular}{|c|c|c|c|c|c|c|c|c|c|}
\hline Type of clinical trial & $\mathrm{FYO3}^{\mathrm{a}}$ & FY04 & FY05 & FY06 & FY07 & FY08 & FY09 & Total U56 period ${ }^{\mathrm{b}}(\%)$ & Total U54 Period ${ }^{\mathrm{c}}(\%)$ \\
\hline Mentor-initiated & 0 & 0 & 0 & 0 & 0 & 0 & 160 & $160(10)$ & $203(29)$ \\
\hline Other cooperative groups ${ }^{d}$ & 271 & 349 & 39 & 75 & 84 & 98 & 82 & $998(60)$ & $209(30)^{d}$ \\
\hline Radiation only & 1 & 0 & 4 & 20 & 9 & 0 & 3 & $37(4)$ & - \\
\hline Radiation/combined treatment & 65 & 9 & 14 & 24 & 19 & 13 & 14 & $158(16)$ & - \\
\hline Cancer control/prevention & 75 & $316^{e}$ & 6 & 9 & 10 & 11 & 14 & $441(44)$ & $71\left(45^{f}\right)$ \\
\hline Pharmaceutical/industry & 0 & 0 & 5 & 1 & 8 & 6 & 31 & $51(3)$ & $14(2)$ \\
\hline Total & $281^{a}$ & 357 & 105 & 180 & 204 & 166 & 385 & $1,678\left(100^{9}\right)$ & 693 (1009) \\
\hline
\end{tabular}

${ }^{a}$ Rapid City had approximately 33 active clinical protocols opened during FY03 in which they accrued 281 patients onto the STAR trial and cooperative group trials (RTOG and NCCTG) ( $n=281)$.

${ }^{b}$ U56 data are through September 30, 2009.

'Data cumulative for FY2010 through 2013 for all U54 grantees.

${ }^{d}$ Rapid City data include patients who were enrolled onto both RTOG and other cooperative group trials. The database structure at this site did not allow segregating the different trial categories (e.g., radiation only, medical/surgical) by only cooperative group trials. For U54 grantees, segregation was also not done.

eIncludes Laredo's accruals to NCl prevention trials, STAR $(n=9)$, and SABOR (300).

${ }^{f}$ Percent accrual to prevention trials out of total $\mathrm{NCl}$ cooperative group trial accruals.

${ }^{g}$ Column percents do not total $100 \%$ due to rounding.

Table 3 | Number of patients screened and eligible for cancer clinical trials.

\begin{tabular}{|c|c|c|c|c|c|c|}
\hline \multirow[t]{2}{*}{ Grantee sites $^{a}$} & \multicolumn{2}{|c|}{$\begin{array}{l}\text { Patients } \\
\text { screened }\end{array}$} & \multicolumn{2}{|c|}{$\begin{array}{l}\text { Patients } \\
\text { eligible }\end{array}$} & \multicolumn{2}{|c|}{$\begin{array}{l}\text { Eligibility } \\
\text { rate }^{\text {b }}(\%)\end{array}$} \\
\hline & $(U 56)^{c}$ & $(U 54)^{d}$ & (U56) & (U54) & (U56) & (U54) \\
\hline Rapid City & 1,601 & 3180 & 457 & 340 & 29 & 11 \\
\hline Centinela Freeman & 28 & - & 28 & - & $100^{e}$ & - \\
\hline New Hanover & 228 & 2578 & 84 & 839 & 37 & 33 \\
\hline Singing River & 982 & 2396 & 166 & 371 & 17 & 16 \\
\hline UPMC McKeesport & 637 & 376 & 84 & 29 & $13^{f}$ & $8^{f}$ \\
\hline Total & 3,476 & 8530 & 819 & 1579 & 24 & 20 \\
\hline
\end{tabular}

${ }^{a}$ Data were not available for Laredo.

${ }^{b}$ Eligibility rate is based on the number of patients eligible divided by the number of patients screened.

¿ U56 data are from FY07 through FY09 only.

${ }^{d}$ Data cumulative for FY2010 through 2013 for all U54 grantees.

${ }^{e}$ Centinela Freeman did not screen all patients.

${ }^{f}$ Only includes data on the UPMC McKeesport site out of a total of five participating hospital at this CDRP site.

facilitated starting in 2006 by Clinical Trial Operating Committee (CTOC) supplemental awards to RCRH, SRHS, and UPMC McKeesport for hiring clinical staff interacting with other oncology specialists and resulted in increased annual patient accruals (Table 2).

Having breadth in the portfolio of trials was critical to overall participation as shown in Table 2. Early on, prevention trials boosted accrual (FY03-04), but later on the increased accrual (FY06 onward) was due to availability of non-radiation trials.
A total of 2,371 patients were accrued during both phases. The $\mathrm{PI} /$ mentor-initiated trials (see Supplementary Material) partially addressed the shortfall of trials suitable for this population as ineligibility remained an accrual barrier (Table 3).

In addition to informing patients about the clinical trials, the patient navigators supported by CRCHD had a positive influence on reducing the number of missed appointments and addressing other barriers to patient participation (9-11). Patient navigation was found to be a critical component at all CDRP sites as 5,147 patients were navigated (Table 4). RCRH and SRHS documented the critical benefit of patient navigators for their patients. Their data helped RCRH to receive a subsequent Komen Foundation grant specifically for a patient navigator to assist all their breast cancer patients, while SRHS's patient navigator became a hospital funded position starting in 2011.

The American Indian (AI) Community Research Representatives (CRRs) were established with CDRP funding at three remote AI reservations in South Dakota. These trained community health educators and Patient Navigators helped RCRH receive a 2-year CDC grant by partnering with the South Dakota Health Department utilizing their CRRs to implement a colorectal screening program for their AI population. Additionally, RCRH partnered with the American Cancer Society to implement the "All Women Count!" Breast and Cervical Cancer Early Detection Program for their AI women at the Pine Ridge Indian Reservation whereby the goals of both ACS and RCRH's Walking Forward Program were implemented (Dr. Petereit, personal communication, April 2014).

\section{TELESYNERGYTM - TELEMEDICINE AND EMPLOYMENT OPPORTUNITIES IN REMOTE COMMUNITIES}

When the CDRP program was initiated, telemedicine was just being established and this program became a pilot test for 
Table 4 | Number of navigated patients per fiscal year by CDRP grantee.

\begin{tabular}{|c|c|c|c|c|c|c|c|c|}
\hline Grantee sites & FY04 & FY05 & FY06 & FY07 & FY08 & FY09 & U56 total \# & U54 total \#b \\
\hline Rapid City & 35 & 77 & 56 & 66 & 184 & 211 & 629 & 786 \\
\hline Laredoc $^{c}$ & 183 & 74 & 90 & NA & NA & NA & 347 & NA \\
\hline Centinela Freeman & $\mathrm{NA}^{\mathrm{d}}$ & 80 & 146 & 166 & 90 & 127 & 609 & NA \\
\hline New Hanover & 2 & 17 & 103 & 117 & 87 & 48 & 374 & 276 \\
\hline Singing River & $\mathrm{NC}$ & NR & NR & 208 & 142 & 325 & 675 & 526 \\
\hline UPMC McKeesport & $\mathrm{NA}^{\mathrm{d}}$ & 96 & 165 & 252 & 217 & 116 & 846 & 79 \\
\hline Total & 220 & 344 & 560 & 809 & 720 & 827 & 3,480 & 1,667 \\
\hline
\end{tabular}

NA, not applicable; NC, data not collected by CDRP site; NR, refers to data not received.

a U56 data were consistently collected beginning in FY2007, Quarter 4 through September 30, 2009.

${ }^{b}$ Data cumulative for FY2010 through FY2013 for all U54 grantees.

'Laredo data are unconfirmed.

${ }^{d}$ Patient navigation program was not active until 2005.

Table 5 | Use of TELESYNERGY ${ }^{\mathrm{TM}}$ for CDRP grantee activities, by fiscal year - U56 phase*

\begin{tabular}{lrrrr}
\hline CDRP grantee activity & \multicolumn{4}{c}{ Number of times used for activity } \\
\cline { 2 - 5 } & FY07, Qtr 4 & FY08 & FY09 & Total \\
\hline Administrative meetings & 5 & 29 & 28 & 62 \\
Research consultations & 21 & 8 & 16 & 45 \\
Patient consultations & 612 & 2,037 & 237 & $2,886^{a}$ \\
Tumor boards & 12 & 113 & 108 & 233 \\
Training/education & 5 & 10 & 20 & 35 \\
Other ${ }^{b}$ & 8 & 4 & 14 & 26 \\
Total & 663 & 2,201 & 423 & 3,287 \\
\hline
\end{tabular}

*Data were consistently collected beginning in FY2007, quarter 4 through September 30, 2009.

${ }^{a} 99 \%$ of the patient consultations via TELESYNERGY ${ }^{\circledR}$ were conducted by Rapid City.

${ }^{b}$ Includes TELESYNERGY ${ }^{\circledR}$ maintenance and patient rounds.

TELESYNERGY ${ }^{\mathrm{TM}}$, a system developed jointly by the NIH Center for Information Technology and NCI. Table $\mathbf{5}$ details how it was used. Videoconferencing facilitated communication between awardees and their mentors for treatment planning (12) and follow-up consultations at remote settings (e.g., South Dakota and Pennsylvania). It was also used among CDRP sites predominantly for training clinical research staff, tumor board conferences, research consultations, and sharing of ideas. Establishing clinical consultation sites at remote centers resulted in saved patient travel time, and it also provided employment opportunities for healthcare workers on the reservations and at satellite Pennsylvania hospitals. These successes were important lessons learned from the conduct of clinical trials and medical care for remote disparities communities (12-14).

\section{DISSEMINATION OF RESULTS}

The CDRP institutions were very active in presentations at local meetings and nationally at the Radiation Therapy Oncology
Table 6 | Number of CDRP-related publications by grantee site.

\begin{tabular}{lrr}
\hline Grantee & \multicolumn{2}{c}{$\begin{array}{l}\text { Number of } \\
\text { publications }\end{array}$} \\
\cline { 2 - 3 } & U56 & U54 \\
\hline Laredo & 1 & NA \\
Rapid City & $23^{\mathrm{a}}$ & 24 \\
Centinela Freeman & 8 & NA \\
New Hanover & 4 & 4 \\
Singing River & 3 & 0 \\
UPMC McKeesport & 14 & 3 \\
Total & 53 & 31 \\
\hline
\end{tabular}

a Includes three book chapters.

Group (now part of NRG Oncology) and the annual ASTRO meetings. Additionally, the CDRP program helped establish an annual ASTRO/NCI Cancer Disparity Symposium to help educate members about cancer disparities issues in the U.S. (see Supplementary Material). All CDRP sites were active to various degrees in publishing results of their cancer disparities program with RCRH being the most productive with publications (Table 6).

\section{DISCUSSION}

As pointed out in a BSA discussion, CDRP took on some of the most difficult challenges to develop clinical trials because of both the disparity populations and the limited previous NIH funding history. Although a higher level of trial participation may have been possible with health disparities sites within the catchment of an NCI-designated Cancer Center and the Division of Cancer Prevention's Minority-Based Community Clinical Oncology Program site, that CDRP successfully reached into the more difficult-toreach areas dispelled the concept that this was impossible and/or that people would reject participation in trials.

To expect health disparities sites to achieve similar rates of clinical trial accrual as major cancer centers and their catchment area is 
not realistic. Implementation takes time and include: (1) developing/training personnel with the necessary research skills and staff to work with government regulations for clinical trials; (2) advising administrators and hospital leadership about the patience needed to develop infrastructure and the wisdom to see the benefit to patients and institution; and (3) establishing physical space and technological facilities needed to conduct research and manage the data.

Having an experienced team from NCI initiate the programs with a visit to the institution was also important. Although there was skepticism based on the experiences that the government would "establish a program, do research, and then leave (14)," this support helped establish trust and personal relationships demonstrating that the government was invested in the community's problems. The initial NCI team included physicians, senior administrators, program directors, and a patient advocate provided by the National Coalition for Cancer Survivorship (15) who emphasized the central importance of community buy-in at the outset.

We suggest that the proposed metrics of success for future disparities efforts include the usual "hard" metrics such as clinical trial participation and publications, but also softer metrics such as: (1) surveys conducted, (2) the number of patients screened, (3) the extent of outreach-recruitment activity, (4) additional research efforts leveraging their infrastructure, (5) staff recruitment, (6) enhanced interest in disparities by cooperative groups (e.g., RTOG) and professional societies (ASTRO), and (7) the ability to secure additional funding. Formal program evaluation as established by NOVA was extraordinarily helpful for the awardees and RRP in assessing progress and determining both gaps and opportunities for progress. The CDRP programs shared data and trials among the awardees, which facilitated the implementation science.

Several years are needed to ramp up clinical trial participation, including the need for surveys and focus groups, time to listen to the community, understanding their needs, assessing barriers and building teams and trust $(5,16)$. Establishing trusting partnerships with the AI community in SD was a potential barrier for the Walking Forward (WF) program that was successfully addressed over time and became evident when there was no difficulty in consenting patients to participate in the ATM genetic study (17). For the advanced stage diseases encountered in minority/underserved populations and limited number of cooperative group studies available, designing PI- and mentor-initiated trials and the later expansion to a broader portfolio of trials beyond radiation oncology resulted in increased accrual for these patient populations (Table 2).

Telemedicine has evolved significantly as the TELESYNERGY ${ }^{\mathrm{TM}}$ system progressed from expensive ISDN phone line systems to a web-based system using off-the-shelf technology. A simplified version is now available for public purchase by outside institutions, both nationally and internationally, with the possibility for support for technical consultations, installation, and training from NIH/NCI if needed.

The establishment of CDRP led to some important changes in the radiation oncology community. The RTOG (now part of NRG Oncology) raised the issue of the need for future "health disparities" clinical trials to fill the gaps noted above. ASTRO developed an annual health disparities scientific program (see Supplementary Material) and additional radiation oncology activities related to cancer disparities on the international level include working with the Program of Action for Cancer Therapy (PACT) of the International Atomic Energy Agency (IAEA) (18)

Perhaps, the greatest challenge now is program sustainability. There were positive outcomes that were not predicted and are strong evidence of the value of investing in NIH/NCI clinical research in health disparities regions. Examples are provided from the three 10-year awardees.

- Rapid City Regional Hospital, in addition to coordinating the state programs mentioned previously, established collaborations with the Native American Cancer Research Corporation (NACR-PI Linda Burhansstipanov, DrPH), the University of Washington-Seattle (Dedra Buchwald, MD), Marquette University (Sheikh Iqbal Ahamed, PhD), and the University of New Mexico (Emily Haozous, $\mathrm{PhD}$ ) to increase cancer screening and palliative care programs in the remote reservations for AIs. In addition, two resident physicians from Harvard University performed their research year at RCRH: Ashleigh Guadagnolo, MD, MPH (radiation oncology) and Sunshine Dwojak, MD (head and neck surgery). RCRH was awarded a 4-year NCI Provocative Questions R01 grant in 2012 by leveraging their CRRs to implement an "American Indian mHealth Smoking Dependency Study" program for the AIs in South Dakota. Several publications resulted from these collaborations with the WFP that ultimately assisted with program sustainability (4-6, 19-21).

- Coastal Carolina Radiation Oncology (CCRO) used their CDRP success in patient accrual to become a full member of NRG Oncology. To sustain their disparity program, CCRO again partnered with NHRMC to form the Southeastern North Carolina (SENC) CCOP, a grant that was awarded in 2013. Because the minority population in SENC is $<50 \%$ of the population, the SENC CCOP could not apply to become a new NCI's Community Oncology Research Program (NCORP) Minority/Underserved Community Site in 2014. Instead, CCRO will revert to full membership in NRG, while NHRMC will likely be an affiliate member of the Alliance group.

- Singing River Health System is building on their mentor relationship with University of Alabama Birmingham (UAB) Cancer Center. It will expand their current patient navigation program via participation as the only Mississippi-based site participating in the CMS Health Care Innovation Challenge award - Deep South Cancer Navigation Network and will receive $\$ 1$ million over 3 years to support 3.5 FTEs for their patient navigation Program.

Philanthropy is another means of potential support, but community resources that major cancer centers or cooperative groups have are not accessible in these health disparities communities. For them to raise sufficient funding to sustain their infrastructure and professional staff and become competitive for the major 
infrastructure, clinical trials and center grants available are not a reasonable expectation.

\section{CONCLUSION}

Through the CDRP program, clinical trials were established in health disparities sites not previously participating in the NCI clinical trials enterprise. The initial success of this pilot program is reassuring and may lead to improved general healthcare awareness for their minority/underserved populations and an increase in the diversity in NCI clinical trials.

Health disparity is an economic issue as much as a "minority" issue. Some health disparities regions have unique populations (i.e., the AIs) and when the study of the biological basis of cancer is conducted for their benefit, trust can be established and "precision/personalized" medicine targeting their illnesses can then be investigated.

The BSA review of the program renewal raised the issue of moral obligation for sustaining programs. Federal agencies support all of the people and the CRCHD has emphasized the large potential value of applying what we already know to help improve cancer outcomes for health disparities communities. While some of what CDRP accomplished met the standard metrics of clinical research as judged by participation numbers, there are aspects that were indeed unique and fall within implementation science. Lessons learned are applicable to future programs. In regard to the moral issue, research programs must pass peer review but, perhaps, different metrics are justified for the disparities sites that suffer from a lack of infrastructure and experience when competing for grants. For all the sites, especially the three 10-year awardees, the CDRP program succeeded in bringing people to clinical trials who previously were on the periphery and without access to the potential advances from these studies. This pilot program showed that reaching health disparities communities who are new to cancer research can be done and the future challenge is not only to broaden access to appropriate cancer care for health disparities populations, but also to sustain these gains.

\section{ACKNOWLEDGMENTS}

We would like to thank Christen Osburn for the initial set-up of the CDRP database for data collection, and Ben Chapman and Jesse Brandys of TerpSys NCI for assistance in the TELESYNER$\mathrm{GY}^{\mathrm{Tм}}$ implementation and continued support to all CDRP sites, the NOVA Research Company evaluation staff for completion of the process and outcomes evaluation reports for both U56 and U54 phases of the CDRP program, the Center to Reduce Cancer Health Disparities for supplemental support for establishment of patient navigation programs at the U56 CDRP sites, the continued support from members of RRP and DCTD, and the advice from members of the EC and BSA. Erica Butler, RRP, provided editorial assistance. CDRP grantees were supported by the following National Cancer Institute grants - CA099010, CA105329, CA105478, CA105486, CA142152, CA142157, and CA142158. Disclaimer: the contents of this manuscript represent the opinions of the authors and are not National Cancer Institute policy.

\section{SUPPLEMENTARY MATERIAL}

The Supplementary Material for this article can be found online at http://www.frontiersin.org/Journal/10.3389/fonc.2014. 00303/abstract

\section{REFERENCES}

1. Frank S. Govern PhD was the Primary Creator of this Innovative Model that Reversed the Traditional Flow of Funding.

2. TELESYNERGY ${ }^{\mathrm{TM}}$. Available at: http://telesynergy.nih.gov/index.html

3. NOVA Research Company. Available at: http://www.novaresearch.com

4. Guadagnolo BA, Cina K, Helbig P, Molloy K, Reiner M, Cook EF, et al. Assessing cancer stage and screening disparities among Native American cancer patients. Public Health Rep (2009) 124:79-89.

5. Guadagnolo BA, Cina K, Koop D, Brunette D, Petereit DG. A pre-post survey analysis of satisfaction with health care and medical mistrust after patient navigation for American Indian cancer patients. J Health Care Poor Underserved (2009) 22:1331-43. doi:10.1353/hpu.2011.0115

6. Guadagnolo BA, Petereit DG, Helbig P, Koop D, Kussman P, Fox Dunn E, et al. Involving American Indians and medical underserved rural populations in cancer clinical trials. Clin Trials (2009) 6:610-7. doi:10.1177/1740774509348526

7. Petereit DG, Rogers D, Govern F, Coleman N, Osburn CH, Howard SP, et al. Increasing access to clinical cancer trials and emerging technologies for minority populations: the Native American project. J Clin Oncol (2004) 22:4452-5. doi:10.1200/JCO.2004.01.119

8. Maguire PD, Meyerson MB, Neal CR, Hamann MS, Bost AL, Anagnost JW, et al. Toxic cure: hyperfractionated radiotherapy with concurrent cisplatin and fluorouracil for stage III and IVA head and neck cancer in the community. Int $J$ Radiat Oncol Biol Phys (2004) 58:698-704. doi:10.1016/S0360-3016(03)01576-1

9. Petereit DG, Molloy K, Reiner ML, Helbig P, Cina K, Miner R, et al. Establishing a patient navigator program to reduce cancer disparities in the American Indian communities of Western South Dakota: initial observations and results. Cancer Control (2008) 15:254-9.

10. Steinberg M, Huang D, Khan D, Forge N, Fremont A, Streeter OE. The use of lay patient navigators to improve quality of care and accrual to clinical trials for radiation oncology patients who are minorities or of low socioeconomic status. Int J Radiat Oncol Biol Phys (2006) 69:S563-4. doi:10.1016/j.ijrobp.2007.07.1829

11. Schwaderer KA, Proctor JW, Martz EF, Slack RJ, Ricci E. Evaluation of patient navigation in a community radiation oncology center involved in disparities studies: a time to completion of treatment study. J Oncol Pract (2008) 4:220-4. doi:10.1200/JOP.0852001

12. Maguire PD, Honaker G, Neal C, Meyerson M, Morris D, Rosenman J, et al. A bridge between academic and community radiation oncology treatment planning. J Oncol Pract (2007) 3:238-314. doi:10.1200/JOP.0752001

13. Schenken LL, Heron DE, Saw CB, Proctor JW. A multi-institutional regional motility model: deployment of TELESYNERGY ${ }^{\mathrm{TM}}$ telemedicine system. $J$ Telemed (2009) 15:377-82. doi:10.1258/jtt.2009.090309

14. Petereit DG, Guadagnolo BA, Wong R, Coleman CN. Addressing cancer disparities among American Indians through innovative technologies and patient navigation: the walking forward experience. Front Oncol (2011) 1:11. doi:10. 3389/fonc.2011.00011

15. National Coalition for Cancer Survivorship. Available at: http://www. canceradvocacy.org

16. Petereit DG, Burhansstipov L. Establishing trusting partnerships for successful recruitment of American Indians to clinical trials. Cancer Control (2008) 15:260-8.

17. Petereit DG, Hahn LJ, Kanekar S, Boylan A, Bentzen SM, Ritter M, et al. Prevalence of ATM sequence variants in Northern Plains American Indian cancer patients. Front Oncol (2013) 3:1-5. doi:10.3389/fonc.2013.00318

18. Programme of Action for Cancer Therapy (PACT). Available at: http://cancer. iaea.org

19. Pandhi N, Guadagnolo BA, Kanekar S, Petereit DG, Smith MA. Cancer screening in native Americans from the Northern Plains. Am J Prev Med (2010) 38:389-95. doi:10.1016/j.amepre.2009.12.027

20. Subrahmanian K, Petereit DG, Kanekar S, Burhansstipanov L, Esmond S, Miner R, et al. Community-based participatory development, implementation, and evaluation of a cancer screening educational intervention among American Indians in the Northern Plains. J Cancer Educ (2011) 26:530-9. doi:10.1007/s13187-011-0211-5 
21. Dwojak SM, Emerick KS, Guadagnolo BA, et al. Cancer knowledge and screening among American Indians. Otolaryngol Head Neck Surg (2012) 147:148.

Conflict of Interest Statement: The authors declare that the research was conducted in the absence of any commercial or financial relationships that could be construed as a potential conflict of interest.

Received: 05 September 2014; accepted: 14 October 2014; published online: 03 November 2014

Citation: Wong RSL, Vikram B, Govern FS, Petereit DG, Maguire PD, Clarkson MR, Heron DE and Coleman CN (2014) National Cancer Institute's Cancer Disparities
Research Partnership program: experience and lessons learned. Front. Oncol. 4:303. doi: $10.3389 /$ fonc.2014.00303

This article was submitted to Radiation Oncology, a section of the journal Frontiers in Oncology.

Copyright (c) 2014 Wong, Vikram, Govern, Petereit, Maguire, Clarkson, Heron and Coleman. This is an open-access article distributed under the terms of the Creative Commons Attribution License (CC BY). The use, distribution or reproduction in other forums is permitted, provided the original author(s) or licensor are credited and that the original publication in this journal is cited, in accordance with accepted academic practice. No use, distribution or reproduction is permitted which does not comply with these terms. 